\title{
Risk factors for hydrocephalus and neurological deficit in children born with an encephalocele
}

\author{
Stephanie L. Da Silva, BA, ${ }^{1}$ Yasser Jeelani, MD,, Ha Dang, MS, ${ }^{2}$ Mark D. Krieger, MD, ${ }^{1}$ \\ and J. Gordon McComb, MD'
} 'Division of Neurosurgery, Children's Hospital Los Angeles; and 2Departments of Neurosurgery and Preventive Medicine, Keck
School of Medicine, University of Southern California, Los Angeles, California

OBJECT There is a known association of hydrocephalus with encephaloceles. Risk factors for hydrocephalus and neurological deficit were ascertained in a series of patients born with an encephalocele.

METHODS A retrospective analysis was undertaken of patients treated for encephaloceles at Children's Hospital Los Angeles between 1994 and 2012. The following factors were evaluated for their prognostic value: age at presentation, sex, location of encephalocele, size, contents, microcephaly, presence of hydrocephalus, CSF leak, associated cranial anomalies, and neurological outcome.

RESULTS Seventy children were identified, including 38 girls and 32 boys. The median age at presentation was 2 months. The mean follow-up duration was 3.7 years. Encephalocele location was classified as anterior $(n=14)$ or posterior $(n=56)$ to the coronal suture. The average maximum encephalocele diameter was $4 \mathrm{~cm}$ (range $0.5-23 \mathrm{~cm})$. Fortyseven encephaloceles contained neural tissue. Eight infants presented at birth with CSF leaking from the encephalocele, with 1 being infected. Six patients presented with hydrocephalus, while 11 developed progressive hydrocephalus postoperatively. On univariate analysis, the presence of neural tissue, cranial anomalies, encephalocele size of at least $2 \mathrm{~cm}$, seizure disorder, and microcephaly were each positively associated with hydrocephalus. On multivariate logistic regression modeling, the single prognostic factor for hydrocephalus of borderline statistical significance was the presence of neural tissue (odds ratio $[\mathrm{OR}]=5.8,95 \%$ confidence interval $[\mathrm{Cl}]=0.8-74.0$ ). Fourteen patients had severe developmental delay, 28 had mild/moderate delay, and 28 were neurologically normal. On univariate analysis, the presence of cranial anomalies, larger size of encephalocele, hydrocephalus, and microcephaly were positively associated with neurological deficit. In the multivariable model, the only statistically significant prognostic factor for neurological deficit was presence of hydrocephalus (OR 17.2, 95\% Cl 1.7-infinity).

CONCLUSIONS In multivariate models, the presence of neural tissue was borderline significantly associated with hydrocephalus and the presence of hydrocephalus was significantly associated with neurological deficit. The location of the encephalocele did not have a statistically significant association with incidence of hydrocephalus or neurological deficit. In contrast to modestly good/fair neurological outcome in children with an encephalocele without hydrocephalus, the presence of hydrocephalus resulted in a far worse neurological outcome.

http://thejns.org/doi/abs/10.3171/2014.10.PEDS14192

KEY WORDS congenital abnormality; encephalocele; hydrocephalus; neurological outcome

$\mathrm{W}$ ITH an estimated global prevalence of $0.8-4$ per 10,000 live births, ${ }^{1,19,20,26-28,30,31}$ encephaloceles, along with anencephaly and myelomeningocele, are common forms of neural tube defects. Defined as cystic congenital malformations in which CNS structures, in communication with CSF pathways, herniate through a defect in the cranium, ${ }^{25}$ encephaloceles are generally classified based on anatomical location. Infants with encephaloceles may often have associated malformations, reported to occur in 36\%-60\% of patients, ${ }^{22,32}$ and include anomalies such as microcephaly, absence of the corpus callosum, optic nerve abnormalities, hypothalamic/pituitary dysfunction, fusion of thalami, schizencephaly, holoprosencephaly, arachnoid cyst, Dandy-Walker malformation,

ABBREVIATIONS $\mathrm{Cl}=$ confidence interval; $\mathrm{OR}=$ odds ratio.

SUBMITTED April 10, 2014. ACCEPTED October 3, 2014.

INCLUDE WHEN CITING Published online February 6, 2015; DOI: 10.3171/2014.10.PEDS14192.

DISCLOSURE The authors report no conflict of interest concerning the materials or methods used in this study or the findings specified in this paper. Biostatistical support was provided by Ha Dang and Wendy Mack, PhD, Director of Biostatistics, Southern California Clinical and Translational Science Institute (NIH/National Center for Research Resources/National Center for Advancing Translational Sciences) through grant no. UL1TR000130. 
Walker-Warburg syndrome, Chiari malformation, craniosynostosis, hypertelorism, hemifacial microsomia, cleft lip/palate, Klippel-Feil malformation, myelomeningocele, and hydrosyringomyelia. . $^{3,517,22,27,34}$

The prognosis for a newborn with an encephalocele depends on a number of factors and includes the location, size, and contents of the encephalocele, along with microcephaly and associated anomalies. ${ }^{4,16,27,34}$ A significant proportion of these children lack normal developmental milestones and may have neurological problems such as ataxia, visual impairment, mental and growth retardation, and seizures. ${ }^{22}$ Previous studies report that prognosis for patients with occipital and parietal encephaloceles is directly related to the presence of neural tissue, hydrocephalus, microcephaly, and accompanying cerebral malformations. ${ }^{6,10,14,20}$ Hydrocephalus carries a significant morbidity in these children, reported to occur in as many as $60 \%-$ $90 \%$ of patients with posterior encephaloceles, in contrast to a much lower incidence of 10\%-15\% in anterior encephaloceles. ${ }^{2,13,23}$ To date, the risk factors associated with hydrocephalus requiring CSF diversion in infants born with an encephalocele have not been fully investigated. In this study, we review our series of patients diagnosed with an encephalocele and analyze the risk factors for hydrocephalus and neurological deficit in these pediatric patients.

\section{Methods \\ Study Population}

We performed a retrospective review of all patients who presented to Children's Hospital Los Angeles with an encephalocele over an 18-year period (1994-2012). Patients included in the study were those diagnosed with encephalocele and who underwent primary surgical repair by the Division of Neurosurgery at our institution. Patients who underwent primary surgical repair of their encephalocele at an outside hospital were excluded from the study as pertinent data were often unavailable. Atretic encephaloceles, considered to be noncystic-i.e., no CSF, nodular or flat, small midline, and posteriorly located behind the coronal suture-were also excluded. Medical records of eligible patients were reviewed by the primary author to extract the following variables: age at presentation, race/ ethnicity, sex, microcephaly, seizure disorder, location of encephalocele, size, contents, presence of hydrocephalus, CSF leakage, associated cranial anomalies, and neurological outcome. Encephalocele location was classified as anterior or posterior based on its relation to the coronal suture. Contents in the encephalocele were initially defined by imaging studies (ultrasonography, CT, and MRI; Figs. 1-3) and subsequently confirmed at the time of operation and by a histopathological report indicating the presence of neural tissue. The presence of progressive hydrocephalus was determined by an abnormal increase in head circumference, full fontanelle, and increase in ventricular size on imaging studies. Cranial anomalies refer to both CNS and bone anatomy abnormalities. Follow-up information was gathered from outpatient visits to the neurosurgeon or neurologist. Assessments from these outpatient follow-up visits were made regarding motor, visual, hearing, cognitive, and verbal developmental modalities. Children who reached all milestones appropriately were considered to have normal neurological status. Children who did not meet all milestones but could not be differentiated as having mild or moderate delay without data from a validated scale were compiled into 1 group. The designation of severe developmental delay was assigned to children who were nonambulatory and nonverbal. This study was conducted with approval from the Institutional Review Board of Children's Hospital Los Angeles.

\section{Statistical Analysis}

Data management and statistical analyses were performed using the program SAS (version 9.3, SAS Institute, Inc.). The independent variables of interest included size of encephalocele in maximal diameter $(\mathrm{cm})$, measured mainly on imaging with a few completed clinically, contents within the encephalocele (neural tissue and/or fluid-filled), microcephaly, presence of associated cranial anomalies, location anterior or posterior to coronal suture, and a seizure disorder. Due to the relatively small sample size, exact logistic regression was used to estimate and test
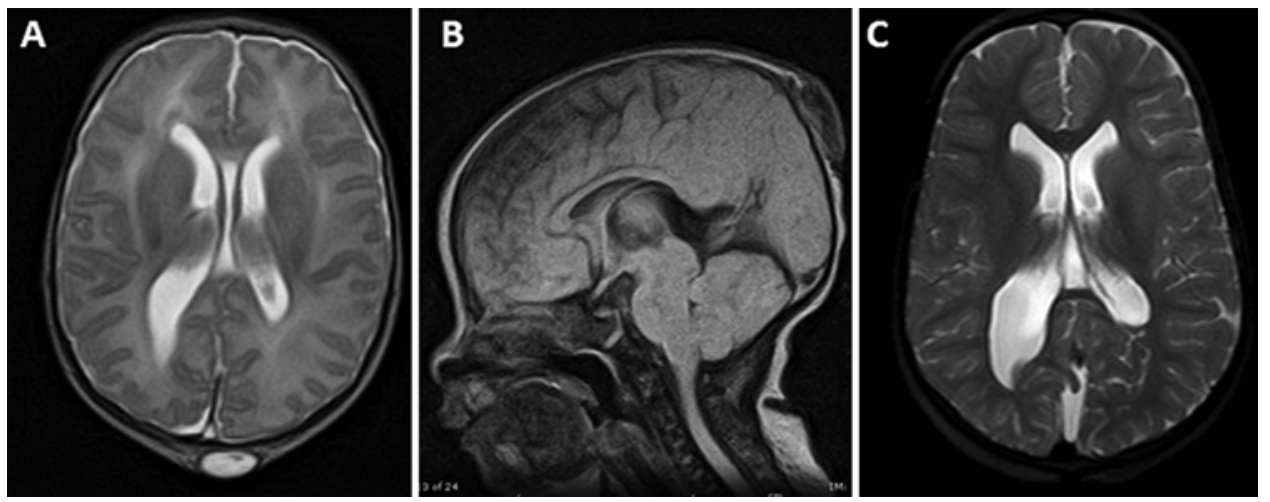

FIG. 1. Magnetic resonance images obtained in a patient with a small encephalocele containing no neural tissue, no hydrocephalus, no intracranial abnormalities, and a normal development. A and B: Axial T2-weighted (A) and sagittal T1-weighted (B) images of a 2-day-old neonate showing a visible mass in the parietal occipital region measuring $1.5 \times 2.6 \mathrm{~cm}$. There was an area of dysplastic skin covering the defect without CSF leakage. C: At two and a half years of age, an axial T2-weighted image shows no progressive hydrocephalus and the toddler has displayed no apparent neurological defects. 



FIG. 2. Images from a patient with a small encephalocele containing neural tissue, hydrocephalus, no intracranial abnormalities, and a mild/ moderate developmental delay. A and B: Sagittal T1-weighted (A) and axial T2-weighted (B) MR images of a 6-day-old neonate demonstrate an occipital encephalocele measuring $2.4 \mathrm{~cm}$ in maximal diameter containing neural tissue. Her encephalocele was repaired at 11 days of age. C and D: Despite normal ventricular size at birth on an axial T2weighted MR image (C), she developed hydrocephalus as shown on a CT scan 2 months later (D), whereupon a ventriculoperitoneal shunt was placed. A year and a half later, at last follow-up, her cognitive examination found mildly delayed developmental milestones.

the associations of these independent variables with the two outcomes (presence of hydrocephalus and developmental delay). Each of the independent variables was first modeled separately to estimate its univariate association with the outcome variable. Multivariable exact logistic re-
TABLE 1. Patient characteristics

\begin{tabular}{cc}
\hline \multicolumn{1}{c}{ Variable } & Value \\
\hline No. of patients & 70 \\
\hline Sex (\%) & $32(46)$ \\
\hline Male & $38(54)$ \\
\hline Female & \\
\hline Age at surgery (mos) & $0-71$ \\
\hline Range & 2 \\
\hline Median & 8.5 \\
\hline Mean & $17(24)$ \\
\hline Hydrocephalus (\%) & 6 \\
\hline Presented & 11 \\
\hline Developed & \\
\hline Neurological outcome (\%) & $28(40)$ \\
\hline Normal & $28(40)$ \\
\hline Mild/moderate delay & $14(20)$ \\
\hline Severe delay & \\
\hline Follow-up (yrs) & $0-19$ \\
\hline Range & 3.7 \\
\hline Mean & 2.2 \\
\hline Median & \\
\hline
\end{tabular}

gression was then used to fit a joint model of independent variables. A variable was considered to be a confounder if it changed the estimated odds ratio (OR) corresponding to any independent variable of interest by more than $15 \%$; statistically nonsignificant factors were excluded from the multivariate model if exclusion did not change the remaining OR estimates by more than $15 \%$. Development or presentation of hydrocephalus and neurological outcome were summarized as ORs, corresponding 95\% confidence intervals (CIs), and exact p values.

\section{Results}

\section{Patient Characteristics}

A total of 70 patients, including 38 girls and 32 boys, were included in the analyses (Table 1). Median age at
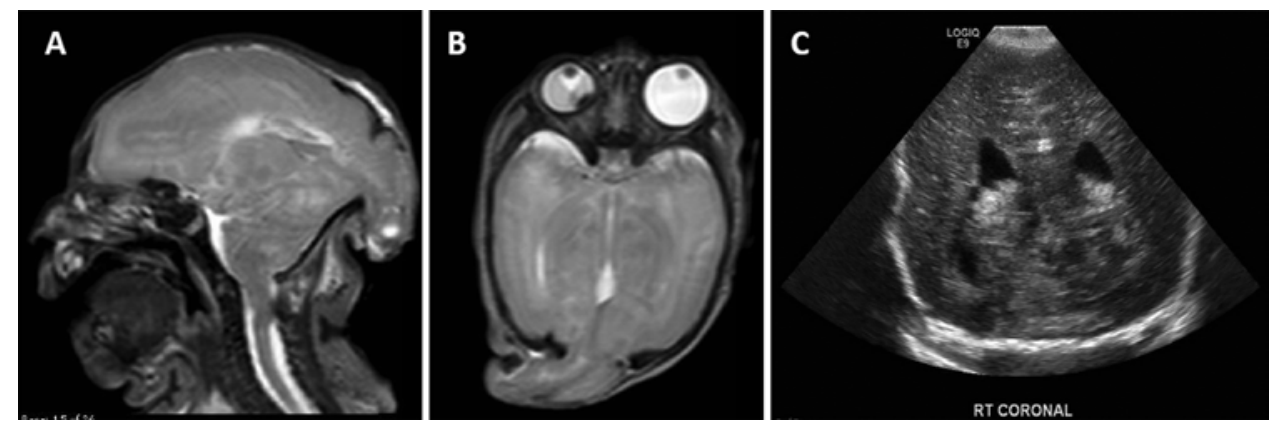

FIG. 3. Images from a patient with a large encephalocele containing neural tissue, hydrocephalus, intracranial abnormalities, and a severe developmental delay. A and B: Preoperative T2-weighted sagittal (A) and axial (B) MR images in a neonate born with a large encephalocele $(5 \mathrm{~cm})$ containing extensive dysplastic neural tissue with associated microcephaly. She was operated on during the 1 st week of life for repair of the encephalocele. Eight days later the child developed a tense fontanelle. C: Moderately enlarged ventricles were demonstrated on head ultrasonography and a ventriculoperitoneal shunt was inserted. At 6 months of age, the child displayed severe developmental delay. 
Risk factors for hydrocephalus and outcome with encephalocele

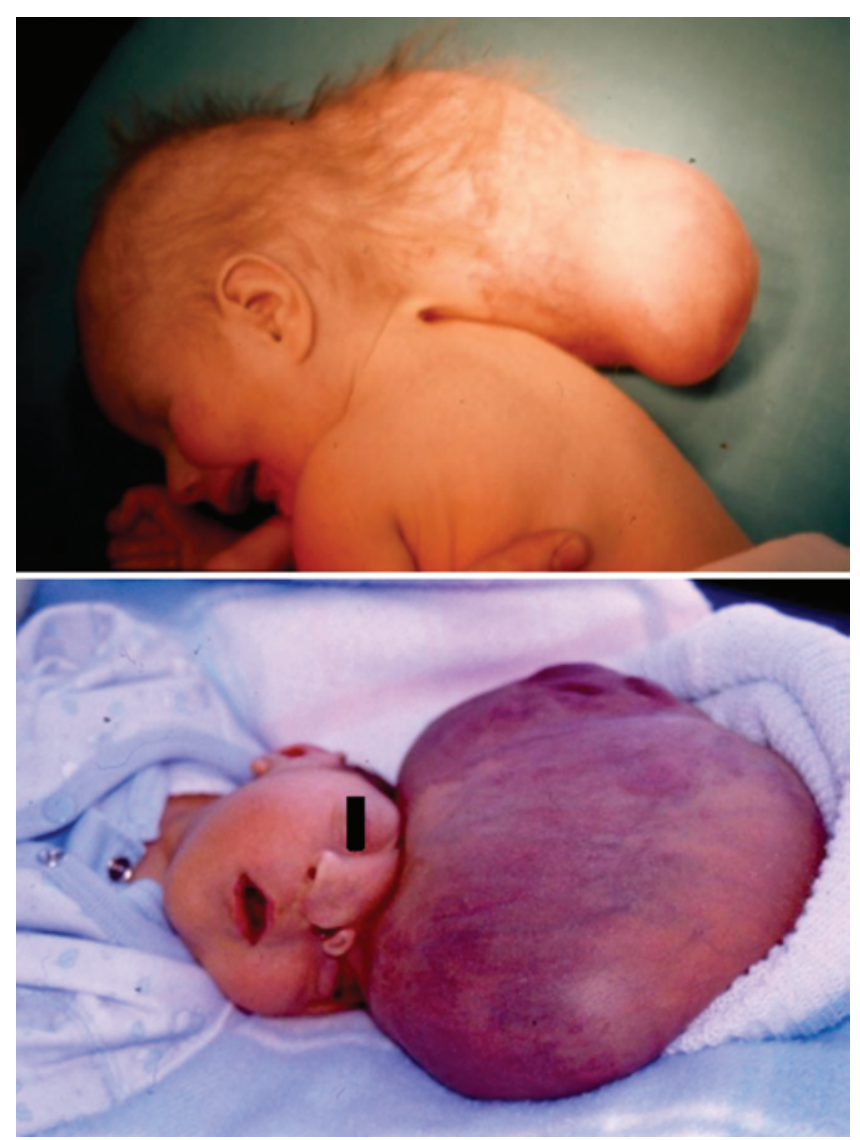

FIG. 4. Photographs of infants with severe encephaloceles. Upper:

This patient was not initially treated due to the severity of her malformation, but as she survived her encephalocele was repaired at 6 months of age and a ventriculoperitoneal shunt was placed to control progressive hydrocephalus. Lower: Due to the severity of this malformation and the poor prognosis, this neonate was not treated and allowed to die (not included in our series). Figure is available in color online only.

resection was 2 months (range 0-71 months). Follow-up ranged from 0 to 19 years, with a mean and median follow-up of 3.7 years and 2.2 years, respectively.

Fifty-six patients $(80 \%)$ presented with a posterior encephalocele, while $14(20 \%)$ presented with an anterior encephalocele. The size of the encephalocele ranged from 0.5 to $23 \mathrm{~cm}$ (Fig. 4 upper) in maximal diameter, with a median of $3.1 \mathrm{~cm}$ and a mean of $4.0 \mathrm{~cm}$. In Fig. 4 lower we see a patient with massive CNS disorganization in whom there would be a poor chance of survival, and the possibility of cognitive development was nonexistent. With parental concurrence, the patient was not treated and subsequently died. This patient was not included in our series. Forty-seven encephaloceles (67\%) contained neural tissue, while in 23 (33\%), neural tissue could not be discerned. Eight infants (11\%) presented with CSF leaking from the encephalocele, with 1 being infected. Nine patients (13\%) developed a seizure disorder following repair. Forty-three patients $(61 \%)$ had associated cranial anomalies (22 with solely cranial anomalies and 21 with a combination of both cranial and extracranial anomalies), 7 patients (10\%) had only extracranial anomalies, while 20 (29\%) had no
TABLE 2. Associated cranial and extracranial anomalies

\begin{tabular}{lc}
\hline \multicolumn{1}{c}{ Anomaly } & Value \\
\hline Cranial & \\
\hline Microcephaly & 13 \\
\hline Agenesis/dysgenesis of corpus callosum & 10 \\
\hline Chiari malformation & 6 \\
\hline Schizencephaly & 3 \\
\hline Arachnoid cyst & 3 \\
\hline Walker-Warburg malformation & 2 \\
\hline Dandy-Walker malformation & 2 \\
\hline Holoprosencephaly & 2 \\
\hline White matter hypoplasia & 1 \\
\hline Sagittal synostosis & 1 \\
\hline Extracranial & 9 \\
\hline Facial dysmorphisms & 6 \\
\hline Cleft lip/palate & 3 \\
\hline Hydrosyringomyelia & 2 \\
\hline Aplasia cutis congenita & 1 \\
\hline Aplasia of bilateral thumbs
\end{tabular}

demonstrable abnormalities. The most commonly associated cranial abnormalities included hydrocephalus, Chiari malformation with or without hydrosyringomyelia, agenesis/dysgenesis of corpus callosum, and microcephaly (Table 2). Commonly associated extracranial anomalies included facial dysmorphisms and cleft lip/palate.

\section{Outcome Data}

All patients underwent surgical excision and repair of the encephalocele. Postoperatively, 2 patients developed a CSF leak, 1 of whom became infected. Of the 8 neonates with CSF leaking from the encephalocele at birth, 1 was infected and another developed progressive hydrocephalus and required CSF diversion. Seventeen patients (24\%) had associated hydrocephalus, with $6(35 \%)$ diagnosed preoperatively, while 11 (65\%) developed progressive hydrocephalus postoperatively (Table 1). Fifteen of the patients with hydrocephalus received shunts. One patient was allowed to die without shunt placement and another did not develop progressive hydrocephalus and thus did not require CSF diversion. Three shunt revisions were performed in total. After a median follow-up of 2.2 years, the overall survival rate was $94 \%$ (66/70). The 4 patients who died all presented with occipital encephaloceles larger than $5 \mathrm{~cm}$ and died of causes unrelated to repair of the encephalocele or a shunting procedure.

In terms of outcome, 14 patients $(20 \%)$ had severe developmental delay, 28 (40\%) had mild/moderate delay, and $28(40 \%)$ were neurologically normal (Table 1$)$. None of the patients with hydrocephalus had a normal neurological outcome; all 17 had some degree of developmental delay, including $11(65 \%)$ with mild/moderate delay and $6(35 \%)$ with severe delay. Two (14\%) of 14 patients with an anterior encephalocele developed progressive hydrocephalus in comparison with $15(27 \%)$ of 56 patients with a posterior encephalocele; the difference in rates was not significant 
TABLE 3. Associations with hydrocephalus outcome according to exact logistic regression

\begin{tabular}{|c|c|c|c|c|c|c|}
\hline \multirow[b]{2}{*}{ Variable } & \multicolumn{2}{|c|}{ Hydrocephalus } & \multicolumn{2}{|c|}{ Univariate } & \multicolumn{2}{|c|}{ Multivariate* } \\
\hline & Yes $(n=17)$ & No $(n=53)$ & OR $(95 \% \mathrm{Cl})$ & $p$ Value & OR $(95 \% \mathrm{Cl})$ & p Value \\
\hline Neural tissue present & $15(88 \%)$ & $32(60 \%)$ & $4.8(1.0-47.8)$ & 0.06 & $5.8(0.8-74.0)$ & 0.09 \\
\hline Cranial anomalies present & $15(88 \%)$ & $28(53 \%)$ & $7.0(1.4-69.6)$ & 0.01 & $2.4(0.3-32.7)$ & 0.63 \\
\hline Size $\geq 2 \mathrm{~cm}$ & $17(100 \%)$ & $39(74 \%)$ & $8.2 \dagger$ (1.2-infinity) & 0.02 & $1.7 \dagger(0.2-$ infinity $)$ & 0.68 \\
\hline Posterior location & $15(88 \%)$ & $41(77 \%)$ & $2.2(0.4-22.3)$ & 0.55 & & \\
\hline Seizure disorder & $7(41 \%)$ & $2(4 \%)$ & $16.8(2.7-188.5)$ & 0.001 & $8.4(0.7-536.8)$ & 0.14 \\
\hline Microcephaly & $7(41 \%)$ & $6(11 \%)$ & $5.63(1.29-26.10)$ & 0.02 & & \\
\hline
\end{tabular}

* Adjusted for age at surgery.

$\dagger$ Indicates a median unbiased estimate.

$(\mathrm{p}=0.49$, Fisher's exact test). Furthermore, $7(50 \%)$ of 14 patients with anterior lesions compared with $35(63 \%)$ of 56 patients with posterior lesions were found to have developmental delay; again, the difference in rates was not significant $(\mathrm{p}=0.39$, chi-square test).

\section{Correlates of Hydrocephalus and Developmental Delay}

Table 3 presents the ORs and 95\% CIs from the univariate and multivariate exact logistic regression models for association with hydrocephalus, as well as the prevalence of the independent variables by hydrocephalus outcome. On univariate analysis, the presence of neural tissue, cranial anomalies, encephalocele size of at least 2 $\mathrm{cm}$, seizure disorder, and microcephaly were each positively associated with hydrocephalus. Age at surgery was a confounder as the addition of this variable to the multivariate model altered the estimated ORs of independent factors by more than $15 \%$. Only the encephalocele content variable remained associated with hydrocephalus at a borderline statistically significant level $(\mathrm{p}=0.09)$ in the multivariate model; other variables were retained in the multivariate model as confounders. Because an encephalocele is a rare condition and only $25 \%$ of the infants in this sample had hydrocephalus, cranial anomalies, size of encephalocele, and seizure disorder were included in the final model in the interest of estimating effect size rather than testing for statistical significance. These independent factors were positively associated with hydrocephalus in this final model. Adjusting for age at surgery, infants with neural tissue within the encephalocele were 5.8 times more likely (95\% CI 0.8-74.0) to present with or develop hydrocephalus after surgery than those with only a fluidfilled encephalocele. Although not statistically significant, children with maximal diameter of the encephalocele of at least $2 \mathrm{~cm}$ were 1.7 times as likely (95\% CI 0.2 -infinity) to present with or develop hydrocephalus. Children with cranial anomalies were 2.4 times as likely (95\% CI $0.3-$ 32.7) and children with a seizure disorder were 8.4 times as likely (95\% CI 0.7-536.8) to present with or develop hydrocephalus. When microcephaly was added to this multivariable model, it was no longer significantly associated with hydrocephalus (adjusted OR 2.2, 95\% CI 0.2-234.7).

Table 4 provides the estimated ORs for associations with developmental delay from univariate and multivariate exact logistic regression models. In univariate models, the presence of cranial anomalies, larger size of encephalocele, hydrocephalus, and microcephaly were positively associated with neurological deficits. In the multivariate logistic regression model adjusted for age at surgery, the presence of hydrocephalus was the most prominent, and only statistically significant, factor (OR 17.2, 95\% CI 1.7infinity). Although not statistically significant, patients with cranial anomalies were 5.4 times as likely $(95 \%$ CI 0.9-56.7) to exhibit developmental delay. In the multivariate model, encephalocele size was not associated with

TABLE 4. Associations with developmental delay according to exact logistic regression

\begin{tabular}{|c|c|c|c|c|c|c|}
\hline \multirow[b]{2}{*}{ Variable } & \multicolumn{2}{|c|}{ Developmental Delay } & \multicolumn{2}{|c|}{ Univariate } & \multicolumn{2}{|c|}{ Multivariate* $^{*}$} \\
\hline & Yes $(n=42)$ & No $(n=28)$ & OR $(95 \% \mathrm{Cl})$ & $p$ Value & OR $(95 \% \mathrm{Cl})$ & $p$ Value \\
\hline Cranial anomalies present & $32(76 \%)$ & $11(39 \%)$ & $4.3(1.4-13.8)$ & 0.008 & $5.4(0.9-56.7)$ & 0.07 \\
\hline Size $\geq 2 \mathrm{~cm}$ & $38(90 \%)$ & $18(64 \%)$ & $5.1(1.3-25.6)$ & 0.02 & $1.2(0.15-11.23)$ & 1.0 \\
\hline Hydrocephalus & $17(40 \%)$ & $0(0 \%)$ & $25.3 \dagger(4.0$-infinity) & $<0.0001$ & $17.2 \dagger(1.7-$ infinity) & 0.01 \\
\hline Neural tissue present & $28(67 \%)$ & $19(68 \%)$ & $1.2(0.4-3.8)$ & 0.87 & & \\
\hline Posterior location & $35(83 \%)$ & $21(75 \%)$ & $1.7(0.4-6.4)$ & 0.58 & & \\
\hline CSF leak & $8(19 \%)$ & $2(7 \%)$ & $3.0(0.5-31.5)$ & 0.30 & & \\
\hline Seizure disorder & $8(19 \%)$ & $1(4 \%)$ & $6.2(0.8-292.1)$ & 0.12 & & \\
\hline Microcephaly & $13(31 \%)$ & $0(0 \%)$ & $17.2 \dagger$ (2.7-infinity) & 0.0009 & $6.1 \dagger(0.5$-infinity) & 0.2 \\
\hline
\end{tabular}

* Adjusted for age at surgery.

$\dagger$ Indicates a median unbiased estimate. 
TABLE 5. A review of comparable series showing the variability in reports on the effects of various factors on long-term neurological outcome in children born with an encephalocele

\begin{tabular}{|c|c|c|c|c|}
\hline \multirow[b]{2}{*}{ Authors \& Year } & \multirow{2}{*}{$\begin{array}{c}\text { No. of } \\
\text { Patients }\end{array}$} & \multicolumn{2}{|c|}{ Factors Affecting Long-Term Neurological Outcome } & \multirow[b]{2}{*}{ Comments } \\
\hline & & Hydrocephalus & Neural Tissue & \\
\hline Lo et al., 2008 & 85 & Yes & Yes & \\
\hline Bui et al., 2007 & 44 & Yes & & Series of cranial vault encephaloceles \\
\hline Martínez-Lage et al., 1996 & 46 & Yes & No & \\
\hline Date et al., 1993 & 24 & Yes & Yes & Series of occipital encephaloceles \\
\hline Shokunbi et al., 1988 & 58 & No & No & Series of sincipital encephaloceles \\
\hline Mealey et al., 1970 & 65 & No & Yes & \\
\hline
\end{tabular}

neurological outcome, and microcephaly was positively but not significantly associated with neurological outcome (OR 6.1, 95\% CI 0.5-infinity).

\section{Discussion}

Encephaloceles probably occur after neural tube closure, as is evidenced by the cerebral cortex or cerebellar tissue contained within the encephalocele in a majority of cases. ${ }^{12,15,18}$ This CNS herniation may occur 8-12 weeks into gestation at the site of local mesenchymal disruption. ${ }^{25}$ While prenatal ultrasonography can be used to detect an encephalocele and the presence or absence of solid tissue within the sac, hydrocephalus is often not present. Various patient series from North America show hydrocephalus is associated with large posterior encephaloceles, although it is more likely to develop following repair of the lesion than be present at birth. In this review we investigate the significant risk factors for both progressive hydrocephalus and developmental delay, while also undergoing a further analysis as to the influence of hydrocephalus on neurological outcome.

In our total cohort of patients, $60 \%$ had some degree of cognitive deficit with $40 \%$ having a normal neurological outcome. This result is higher than the 16\%-31\% who were "physically and/or mentally disabled" reported by Tsuchida et al., ${ }^{33}$ Docherty et al., ${ }^{11}$ Date et al., ${ }^{9}$ Macfarlane et al., ${ }^{21}$ and Martínez-Lage et al. ${ }^{24}$ Among the hydrocephalic patients in our study, none had a normal neurological outcome. Our review has confirmed previous findings that hydrocephalus is significantly associated with cognitive deficit in patients with encephaloceles. ${ }^{8,9,19}$ While patients with posterior encephaloceles had a higher rate of progressive hydrocephalus (15/56) and developmental delay $(35 / 56)$ than those with anterior lesions $(2 / 14$ and $7 / 14$, respectively), there was no statistically significant difference between these rates, confirming the finding by Lo et al. ${ }^{19}$ A sample of large reviews is shown in Table 5 for comparison with our results.

The limitations of this study include the retrospective nature of this review, small sample size, and inability to evaluate patients on a uniform cognitive outcome scale. Some infants with normal developmental milestones who were classified as neurologically normal, on longer followup may be identified as having learning disabilities, and thus would fall into the mild/moderate developmental delay category.

\section{Conclusions}

In multivariate models, the presence of neural tissue was significantly associated with hydrocephalus, and the presence of hydrocephalus was significantly associated with neurological deficit. The location of an encephalocele did not have a statistically significant association with incidence of hydrocephalus or neurological deficit. In contrast to modestly good/fair neurological outcome in children with an encephalocele without hydrocephalus, the presence of hydrocephalus resulted in a far worse neurological outcome. We believe that the information gleaned from this review of our series can help to guide prenatal or neonatal counseling.

\section{References}

1. Agthong S, Wiwanitkit V: Encephalomeningocele cases over 10 years in Thailand: a case series. BMC Neurol 2:3, 2002

2. Alexiou GA, Sfakianos G, Prodromou N: Diagnosis and management of cephaloceles. J Craniofac Surg 21:15811582,2010

3. Ambekar S, Devi BI, Shukla D: Large occipito-cervical encephalocele with Chiari III malformation. J Pediatr Neurosci 6:116-117, 2011

4. Andarabi Y, Nejat F, El-Khashab M: Progressive skin necrosis of a huge occipital encephalocele. Indian J Plast Surg 41:82-84, 2008

5. Aslan A, Eser O, Doğru O, Aktepe F, Yurumez Y, Fidan H: Occipital mega encephalocele associated with acute inflammation. Pediatr Neurosurg 43:65-66, 2007

6. Brown MS, Sheridan-Pereira M: Outlook for the child with a cephalocele. Pediatrics 90:914-919, 1992

7. Bui CJ, Tubbs RS, Shannon CN, Acakpo-Satchivi L, Wellons JC III, Blount JP, et al: Institutional experience with cranial vault encephaloceles. J Neurosurg 107 (1 Suppl):22-25, 2007

8. Czech T, Reinprecht A, Matula C, Svoboda H, Vorkapic P: Cephaloceles - experience with 42 patients. Acta Neurochir (Wien) 134:125-129, 1995

9. Date I, Yagyu Y, Asari S, Ohmoto T: Long-term outcome in surgically treated encephalocele. Surg Neurol 40:125-130, 1993

10. Diebler C, Dulac O: Cephaloceles: clinical and neuroradiological appearance. Associated cerebral malformations. Neuroradiology 25:199-216, 1983

11. Docherty JG, Daly JC, Carachi R: Encephaloceles: a review 1971-1990. Eur J Pediatr Surg 1 (Suppl 1):11-13, 1991

12. Emery JL, Kalhan SC: The pathology of exencephalus. Dev Med Child Neurol Suppl 12 (Suppl 22):51-64, 1970

13. Gamache FW Jr: Treatment of hydrocephalus in patients with 
meningomyelocele or encephalocele: a recent series. Childs Nerv Syst 11:487-488, 1995

14. Guthkelch AN: Occipital cranium bifidum. Arch Dis Child 45:104-109, 1970

15. Hendrick EB: Encephaloceles, in Wilkins RH, Rengachary SS (eds): Neurosurgery, ed 2. New York: McGraw-Hill, 1995, pp 2087-2091

16. Kiymaz N, Yilmaz N, Demir I, Keskin S: Prognostic factors in patients with occipital encephalocele. Pediatr Neurosurg 46:6-11, 2010

17. Kotil K, Kilinc B, Bilge T: Diagnosis and management of large occipitocervical cephaloceles: a 10-year experience. Pediatr Neurosurg 44:193-198, 2008

18. Lemire RJ, Loesser JD, Leech RW, Alvord EC: Normal and Abnormal Development of the Human Nervous System. Hagerstown, MD: Harper \& Row, 1975

19. Lo BW, Kulkarni AV, Rutka JT, Jea A, Drake JM, LambertiPasculli M, et al: Clinical predictors of developmental outcome in patients with cephaloceles. J Neurosurg Pediatr 2:254-257, 2008

20. Lorber J: The prognosis of occipital encephalocele. Dev Med Child Neurol 9 (Suppl 13):75-86, 1967

21. Macfarlane R, Rutka JT, Armstrong D, Phillips J, Posnick J, Forte V, et al: Encephaloceles of the anterior cranial fossa. Pediatr Neurosurg 23:148-158, 1995

22. Mahajan C, Rath GP, Dash HH, Bithal PK: Perioperative management of children with encephalocele: an institutional experience. J Neurosurg Anesthesiol 23:352-356, 2011

23. Mahapatra AK: Anterior encephalocele - AIIMS experience a series of 133 patients. J Pediatr Neurosci 6 (Suppl 1):S27S30, 2011

24. Martínez-Lage JF, Poza M, Sola J, Soler CL, Montalvo CG, Domingo R, et al: The child with a cephalocele: etiology, neuroimaging, and outcome. Childs Nerv Syst 12:540-550, 1996

25. McComb JG: Encephaloceles, in Youmans JR (ed): Neurological Surgery: A Comprehensive Reference Guide to the Diagnosis and Management of Neurosurgical Problems, ed 4. Philadelphia: WB Saunders, 1996, pp 829-842

26. Mealey J Jr, Dzenitis AJ, Hockey AA: The prognosis of encephaloceles. J Neurosurg 32:209-218, 1970

27. Raja RA, Qureshi AA, Memon AR, Ali H, Dev V: Pattern of encephaloceles: a case series. J Ayub Med Coll Abbottabad 20:125-128, 2008

28. Rowland CA, Correa A, Cragan JD, Alverson CJ: Are encephaloceles neural tube defects? Pediatrics 118:916-923, 2006

29. Shokunbi MT, Olumide AA, Adeloye A: Sincipital encephalocoeles: a review of clinical presentations and methods of surgical repair in Ibadan, Nigeria. Br J Neurosurg 2:497501,1988

30. Siffel C, Wong LY, Olney RS, Correa A: Survival of infants diagnosed with encephalocele in Atlanta, 1979-98. Paediatr Perinat Epidemiol 17:40-48, 2003

31. Simpson DA, David DJ, White J: Cephaloceles: treatment, outcome, and antenatal diagnosis. Neurosurgery 15:14-21, 1984

32. Stoll C, Dott B, Alembik Y, Roth MP: Associated malformations among infants with neural tube defects. Am J Med Genet A 155A:565-568, 2011

33. Tsuchida T, Okada K, Ueki K: [The prognosis of encephaloceles (author's transl).] No Shinkei Geka 9:143-150, 1981 (Jpn)

34. Upadhyaya V, Upadhyaya DN, Sarkar S: Sincipital encephalocele with corpus callosum agenesis and intracranial lipoma: a case report. Indian J Radiol Imaging 15:507-510, 2005

\section{Author Contributions}

Conception and design: McComb, Da Silva, Jeelani. Acquisition of data: Da Silva. Analysis and interpretation of data: McComb, Da Silva, Jeelani, Dang. Drafting the article: Da Silva, Jeelani, Dang, Krieger. Critically revising the article: McComb, Da Silva, Krieger. Reviewed submitted version of manuscript: all authors. Approved the final version of the manuscript on behalf of all authors: McComb. Statistical analysis: Da Silva, Dang. Study supervision: McComb, Krieger.

\section{Correspondence}

J. Gordon McComb, Division of Neurosurgery, Children's Hospital Los Angeles, 1300 N. Vermont Ave., Doctor's Tower, Ste. 1006, Los Angeles, CA 90027. email: gmccomb@chla.usc.edu. 